\title{
LAS DOS CARAS DE LA INMUNIDAD: RESPUESTA TH
}

\author{
THE TWO FACES OF IMMUNITY: ANSWER TH \\ Edwin Rolando Castillo-Velarde ${ }^{1, a}$
}

\section{RESUMEN}

Objetivos: Las citokinas poseen una acción pleiotrópica que intervienen tanto en la salud como en la enfermedad, que es mediado por la respuesta linfocitaria T helper. Existe una interacción no excluyente entre la respuesta Th efectora/reguladora, de la cual depende el éxito de procesos fisiológicos y fisiopatológicos en su disregulación. En esta revisión, mencionaremos algunos ejemplos representativos de la disregulación Th. En el embarazo recae en una respuesta inicial mediada por Th1, y en su defecto ocurren mecanismos relacionados a la preeclampsia. Un disbalance con predominio Th2 es descrito en el asma, pero por otro lado es una respuesta relacionada a la sobrevida de un injerto en el transplante de órganos. Asimismo, mecanismos relacionados a un déficit Th1 subyacen en el modelo inmunogénico del cáncer. De la comprensión de este equilibrio se desprende la capacidad de modificar los diferentes escenarios clínicos en un concepto inmunológico.

Palabras clave: Citokinas,Th; Preeclampsia; Transplante; Cáncer; Asma. (fuente: DeCS BIREME)

\begin{abstract}
Objective: Cytokines have pleiotropic action involving health and disease through $\mathrm{T}$ helper lymphocyte response. An interactive response effector/regulatory or Th response, is related with physiological and pathophysiological processes. Pregnancy has an initial response mediated by Th1, but in lack response, there are mechanisms related to preeclampsia. A predominant Th2 imbalance is described in asthma, however, this response is related to a graft survival of transplanted organs. Mechanisms related to a deficit Th1 is regard to the inmunogenic cancer model. Understanding this balance is important to modify clinical contexts with an immunological concept.
\end{abstract}

Key words: Cytokines, Th; Preeclampsia; Transplant; Cáncer; Asthma. (source: MeSH NLM)

\section{INTRODUCCIÓN}

Las citokinas son una familia de pequeñas proteínas, que intervienen en la señalización, crecimiento, diferenciación y proliferación celular; así como en la apoptosis, quimiotaxis, inmunomodulación y transformación de los diversos isotipos de inmunoglobulinas. Poseen efectos pleiotrópicos, y pueden agruparse en diferentes subpoblaciones si son derivadas de los linfocitos $T$ helper, como sigue: Th1: IL-2, IFN- $\gamma$ y IL-12. Th2: IL-4, 5, 9, 13 y 25. Th3: IL10 , TGF- $\beta$, y Th17: Il-17, subdividido a su vez de Th17A a Th17F, IL 6, 21, 23 (Tabla 1). Las citokinas, también pueden ser clasificadas según su función o por su mecanismo fisiopatogénico. Asimismo, la producción de citokinas puede provenir también de células no inmunes como fibroblastos ${ }^{1,2}$.
Desde un punto de vista funcional, el grupo Th1 genera una respuesta celular. De este grupo, la IL-2, interviene en la sobrevida del linfocito $T$ y progresa el linfocito $T$ de fase G1 a S. El INF $\gamma$ interviene en la inmunidad innata. Estas citokinas se vinculan con las células NK, las cuales poseen una respuesta Th1, ya que responden a la IL-2, 12 y INF $\gamma$. De esta manera las células NK cumplen su función de destrucción de células tumorales y células infectadas por virus. Muchas de las IL de este grupo poseen acción pro-inflamatoria como el INF- $\gamma$, IL-12, pero también lo es la IL-4.

El grupo Th2, posee una mayor tendencia para una respuesta humoral. Es mal conocida por tener una acción "anti-inflamatoria", pues posee también citokinas pro-inflamatorias, aunque en menor medida 
que la respuesta Th1. Anteriormente se vinculaba la presencia de IL-10 en su grupo, pero actualmente se identifica en un grupo independiente. El grupo Th3, se relaciona con la IL-10. Esta interleukina fue identificada inicialmente como un producto de las células Th2 en murinos. Ejerce una acción anti-inflamatoria, y existen múltiples reportes sobre su deficiencia en enfermedades con un perfil reactivo o inflamatorio, asimismo se encuentra en grandes concentraciones en la leche materna ${ }^{1-6}$.

El grupo Th17, con la IL17, tiene a su vez, diversas familias, de los cuales la IL-17A, interviene en desarrollo de autoinmunidad, inflamación y tumores. La IL-17F se relaciona a los mecanismos de defensa del huésped

Tabla 1. Subpoblaciones Th de linfocitos T helper. en mucosas. La IL-17E amplifica la respuesta Th2. La IL17A y $\mathrm{F}$ son producidos por diferentes tipos de células que incluyen a células CD4, CD8, células no inmunes como fibroblastos y células endoteliales, y también en respuesta a otras IL tales como la 1, 6 y TGF-beta. Poseen una respuesta amplia, activando células $T, B$, producción de anticuerpos y producción de péptidos reguladores como el VEGF5 ${ }^{5}$. Se ha observado que el grupo Th 17 se halla enriquecido en tejidos epiteliales de barrera como piel, pulmones e intestino. Este grupo tiene la particularidad de que puede promocionar y continuar su expresión como Th1, sin embargo la diferencia con este grupo es que no incrementa las células de memoria, en procesos inmunológicos de largo plazo'.

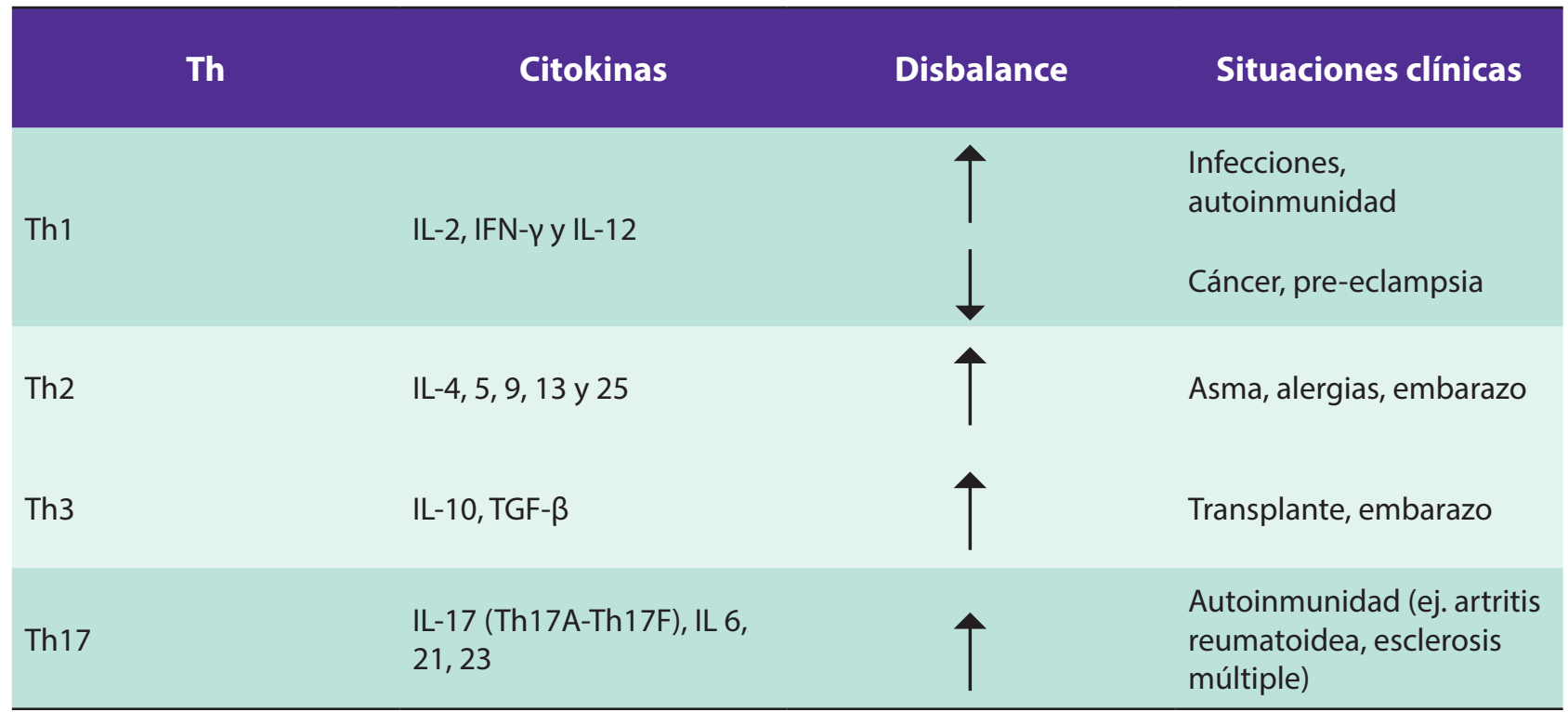

Si bien la definición entre Th1 y Th2 en humanos no es tan clara como en murinos, la evidencia soporta un disbalance entre ambos tipos en las diversas alteraciones de la respuesta inmune. Sin embargo tampoco debe ser visto sus funciones en un paradigma de beneficio vs daño, ya que en muchas situaciones encontraremos necesidades fisiológicas de la respuesta Th1, como también consecuencias patológicas. Asimismo, no existe una clasificación simplista Th1/th2 por la complejidad que puede recaer en diversas situaciones clínicas. A continuación repasaremos algunos escenarios clínicos para comprender este disbalance.

\section{Asma}

En este caso las citokinas, pueden ser clasificadas en:

1. Asociadas a la respuesta eosinofílica (IL-5).

2. Regulación de la lg E (IL-4, 9, 13).
3. Remodelado bronquial (TGF- $\beta$, PDGF, IL-6).

4. Citokinas inmunomoduladores (IL-10).

En el asma atópica es conocida la predominancia de la respuesta Th2 sobre la Th1. La IL-4, interviene en la activación de los linfocitos $B$ y producción de $\lg E$, incrementa la expresión de MHC-II, favorece la expresión antigénica, y promueve la expresión de VCAM-1 para el reclutamiento de eosinófilos. En su contraregulación, la activación de la IgE por la IL-4, puede ser reducida por la expresión de citokinas Th1 como el INF Y (Figura 1). La IL-10 (Th3), que en un pulmón sano, constituye en los macrófagos alveolares su mayor fuente de producción, se encuentra reducida en los pacientes con asma. Las acciones inmunomoduladores de la IL-10 en el pulmón incluyen la inhibición de la migración eosinofilica, evita la liberación de quimiokinas como la IL-8, y disminuye la producción de IL-42,7,8,9. 


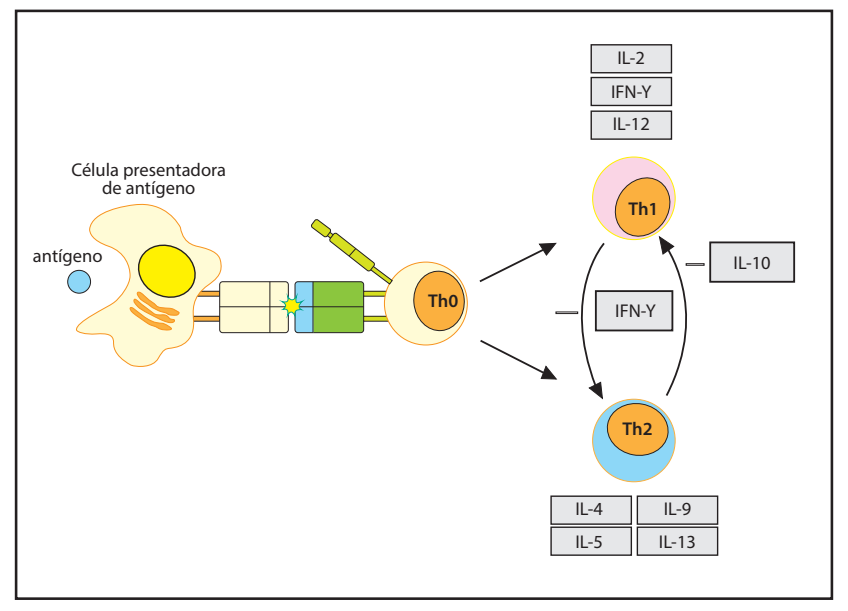

Figura 1. Regulación de las células T. Expresión de

citokinas y patrón Th1 y Th2 [(figura adaptada de (2)].

Por otro lado, en otras enfermedades tenemos una visión inversa sobre la relación Th1/Th2, por ejemplo en esclerosis múltiple y artritis reumatoidea, existe una enfermedad autoinmune mediada por Th1. En esta última, recae el uso actual de inmunosupresores como bloqueantes del TNFa, que también interviene en la regulación $\operatorname{Th} 1^{10}$.

\section{Pre-eclampsia}

Durante el desarrollo placentario, el trofoblasto se desarrolla en dos tipos de trofoblastos invasivos: sincitiotrofoblasto multinuclear y el trofoblasto extravelloso. Esta diferenciación es importante para una adecuada formación de la circulación uteroplacentaria que ocurre a las 12-13 semanas de gestación. El remodelado vascular a través de la invasión de trofoblasto extravelloso, incluye el reemplazo de células musculares lisas de las arterias espirales. La consecuencia de una circulación placentaria adecuada permite un gran flujo sanguíneo, una baja resistencia y una menor velocidad del flujo sanguíneo a nivel del espacio intervelloso (que evita el flujo turbulento, disminuye el "shear stress" y maximiza el intercambio por difusión) ${ }^{11,12}$

Bajounavisióngeneral, un embarazo sincomplicaciones, posee un adecuado balance Th1/Th2. Si se considera el producto, como un semi-injerto, las citokinas Th1 (INF- $\gamma$ ) pueden promover el rechazo del injerto y comprometer el embarazo. Mientras que las citokinas Th2 (IL-4), inhiben la respuesta Th1, promoviendo la tolerancia al injerto y sobrevida del feto. Las IL 4, 5 y 10, son detectadas en la interface feto-materna durante todo el periodo de gestación, en cambio el INF- $\gamma$, es detectable solo en el primer periodo ${ }^{13,14}$.

Un perfil tolerogénico se relaciona con hormonas como la progesterona, por ser un potente inductor de las citokinas Th2 y de IL-10. La hCG disminuye las células Th1, CD8, macrófagos, y aumenta las Th2, IL-10 y células CD4+/CD25+ (con acción inmunoreguladora). Además constituye un regulador de las células uNK (NK uterinas), que intervienen en una adecuada placentación ${ }^{15}$.

Las células UNKson de dos tipos:Las eNK (endometriales, encontradas durante el ciclo menstrual) y las dNK (deciduales). De los leucocitos deciduales, las células NK se encuentran en una mayor proporción de 70\%, siendo 10 veces mayor que en sangre periférica. En su activación interviene la IL-15 que es producida por el incremento de la progesterona de las células estromales. Estas células dNK intervienen en la invasión del trofoblasto extravelloso en la decidua uterina y miometrio interno, y en la remodelación de las arterias espirales y angiogénesis (producen VEGF y PGF). (Figura 2). Producto de su activación, las dNK producen INF- $\gamma$, TGF- $\beta 1$ y TNF- $\alpha$, por lo cual se determina un perfil Th1, de importancia funcional. Estas células dNK si bien poseen baja capacidad citotóxica (baja expresión de perforina y granzima B), están capacitadas para responder frente a una infección intrauterina. El contrabalance de este perfil, dependerá de un perfil más tolerogénico relacionado con la presencia de IL-10 y la contraregulación hormonal ${ }^{16,17}$.

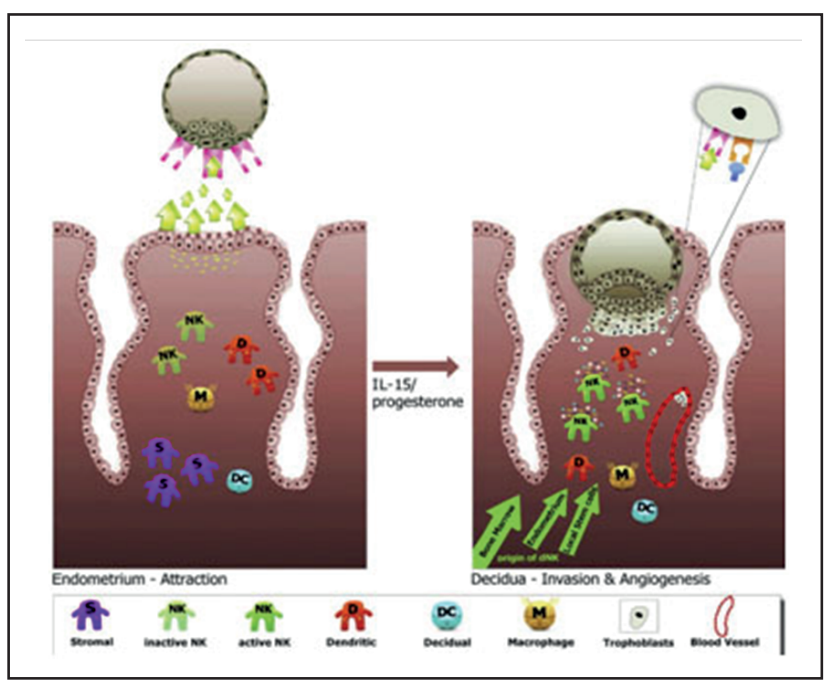

Figura 2. Células NK endometriales y deciduales. Se observa la participación de las dNK en la invasión del trofoblasto y en la angiogénesis [(figura adaptada de (16)].

Otra célula decidual, es el macrófago, que le sigue en proporción a las células NK. Estas células son importantes, pues son las principales células presentadoras de antígeno deciduales, por lo que intervienen en el aloreconocimiento. No obstante, adoptan más bien un perfil mas tolerogénico, ya que la presentación antigénica del producto a los linfocitos $T$ maternos es limitada, ya que el trofoblasto no expresa HLA tipo I (A y B) ni tipo Il, y los macrófagos deciduales, 
poseen una mayor actividad de IDO (indoleamina 2,3 dioxigenasa), que se relaciona con la exposición de CTLA-4, que es una proteína que inhibe la reactividad de un linfocito $\mathrm{T}^{18}$.

Un adecuado balance Th1/Th2, no se representa pues por un paradigma simplista Th1 "malo", que induce aborto y Th2 "bueno" que lleva a un embarazo exitoso. Pues existe una interacción inmune dinámica, como el de las células NK, que en su respuesta Th1, produce INF- $\gamma$ que es esencial para la remodelación de las arterias espirales y disminuye el riesgo de pre-eclampsia, pero por otro lado, también puede producir TGF- $\beta$ que con su co-receptor endoglina, disminuye la expresión de NO en la placenta y aumenta el riesgo de pre-eclampsia. Tenemos también el caso de un déficit de IL-10, que puede manifestarse en el aborto recurrente. Por lo tanto una adecuada regulación Th1/Th2, reactivo/ tolerogénico según las demandas fisiológicas, son necesarias para evitar consecuencias patológicas.

\section{Transplante}

Uno de los principales factores que limita la sobrevida de un injerto a largo plazo, es el rechazo al mismo. La respuesta inmune al injerto es principalmente dependiente de las células $T$, a través del reconocimiento de los antígenos que son expresados por el complejo mayor de histocompatibilidad-MHC. Normalmente el MHC tipo I presenta antígenos adquiridos endógenamente a las células T CD8, mientras el MHC tipo Il presenta los antígenos adquiridos exógenamente a las células T CD4. La activación final propia del linfocito T requerirá además del estimulo de otras moléculas (coestimulación) a través de la unión entre CD28 y CD154 linfocitarios con los CD80-86 y CD40 de la célula presentadora de antígeno del MHC. Por otro lado, el CTLA4-Ig, que es una proteína que inhibe la activación del CD28, posee un rol tolerogénico. En la disfunción crónica de un injerto los mecanismos inmunes recaen en la presentación a cargo del MHC tipo II a las células $\mathrm{T}$ CD4. El rechazo se asocia estrechamente al INFY, como citokina prototipo del grupo Th1, y que puede ser producida por linfocitos $\mathrm{T}$ activados, células NK y macrófagos ${ }^{19-21}$. Por otro lado, la tolerancia y el mantenimiento de un injerto, dependerá entre otros factores de la capacidad inmunoreguladora. Los inmunosupresores inhiben el reclutamiento de células T activadas y algunos como la globulina anti-timocítica (ATG) y la rapamicina, han demostrado capacidad de promover células $T$ reguladoras.

Las células T regulatorias (Treg) pueden ser clasificadas como innatas o adaptativas. Las células $T$ regulatorias innatas, desarrolladas durante la ontogenia timica, expresan el gen Foxp3, y generan células CD4+CD25+ (expresan CD4 y el receptor de la IL-2, CD25) las cuales representan el 5-10\% de las células T CD4 periféricas. Estas células Treg se encargan de la prevención de enfermedades autoinmunes y del mantenimiento de la auto-tolerancia. Estas células son anérgicas, pero una vez activadas inhiben la proliferación y producción de citokinas de células T CD4 y CD8, principalmente al inhibir a la IL-2.

Las células $\mathrm{T}$ regulatorias adaptativas se generan desde las células T CD4 maduras, que en un 90-95\% de ellas no expresan el gen Foxp3. Bajo condiciones de estimulación relacionadas con el grupo Th3 e IL10, se vuelven Treg generando la expresión de Foxp3, a diferencia de aquellas que no lo expresan, que se comportan como células T efectoras (Figura 3). Se ha identificado también como Treg al CD8+CD28-. La investigación en el trasplante se centra en promover la vida del injerto y por lo tanto en el entendimiento de los diferentes mecanismos tolerogénicos. Otras células estudiadas son las células dendríticas (DC) pues al ser las principales células presentadoras de antígeno, tienen un rol en la inducción de tolerancia. Estas células en su fenotipo inmaduro o semimaduro, estimulan una respuesta Th2, bloquean la coestimulación a través del CTLA4-Ig, y además son afectadas por citokinas como la IL-10, con la capacidad de estimular a células $T$ reguladoras ${ }^{22-28}$.

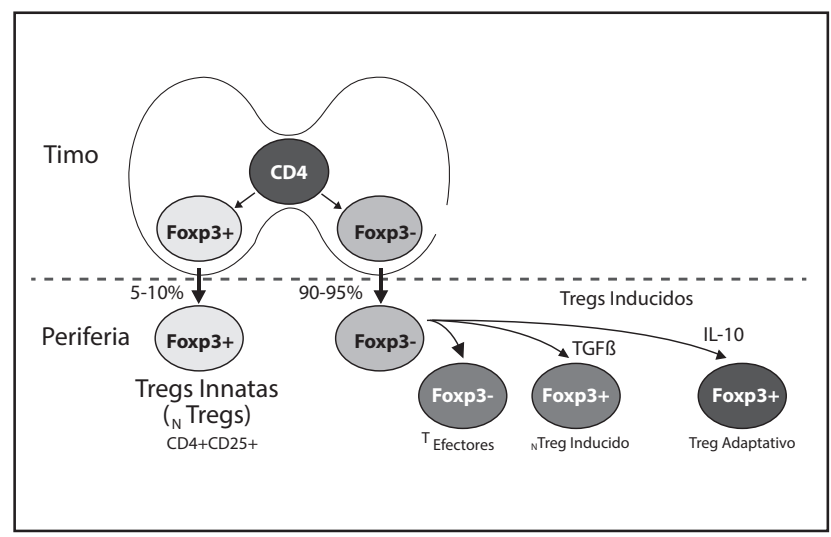

Figura 3. Células CD4 reguladoras. Se observa la expresión de Foxp3 en las células Treg innatas. Algunas células Tregs inducidos expresarán Foxp3, bajo influencia de IL 10, TGF- $\beta$ [(figura adaptada de (16)].

\section{Cáncer}

El cáncer ha sido vinculado a un desorden inmune del balance inflamatorio/antiinflamatorio, células $T$ reguladoras/células T efectoras, Th1/Th2; habiéndose observado un incremento en su incidencia de igual forma que los desordenes autoinmunes o inmunoalérgicos. La oncogénesis estaría favorecida 
por un déficit Th1 o estado de anergia inmune como explicaremos a continuación. Si bien en algunos casos, se vincula a la infección como promotora del cáncer, esta causa se ha limitado en un 15\%, y principalmente a organismos como Epstein Barr, HHV-8, HTLV-1, HPV y hepatitis B y C. Más bien, se ha vinculado la presencia de infecciones como factores que reducirían la presencia del cáncer. En 1891, el Dr. William Coley inoculó a nivel intratumoral cepas inactivadas de Streptococcus pyogenes y Serratia marcescens, en un esfuerzo de reproducir remisiones espontaneas de sarcomas, que observó en algunos pacientes que habían desarrollado erisipela. En las últimas décadas, se han descrito estudios epidemiológicos vinculando el riesgo de desarrollar melanoma en forma inversamente proporcional al número de infecciones previas, y en el África, se ha descrito una menor incidencia de cáncer gástrico asociado a una mayor infección por $\mathrm{H}$. pylori, a diferencia de otros países ${ }^{28,29}$.

Desde 1990, se han realizado estudios experimentales en murinos, resaltando la importancia que posee el INF $\gamma$, ya que ratas deficientes de este factor eran más susceptibles a la carcinogénesis. Se reconoce que el sistema inmune intervendría en la prevención del cáncer de la siguiente forma: 1. Protección contra infecciones virales, disminuyendo la producción de tumores inducidas por virus, 2. Previene un estado inflamatorio que favorece la tumorogénesis, 3. Elimina células tumorales. Este último proceso dinámico, a su vez se realizaría en diferentes pasos:

1. Eliminación: El sistema inmune y adaptativo trabajan en conjunto detectando la presencia de un tumor y destruyéndolo, estimulándose señales de daño pro-inflamatorio como el INFY. Si bien el sistema innato protege contra el desarrollo de tumores, se agregaría también en forma coordinada la activación del sistema adaptativo bajo la expresión de células $T$ efectoras CD4, CD8.

2. Equilibrio: Se da cuando variantes de células tumorales sobreviven a la fase de eliminación, en donde el sistema inmune limita a estas células en un estado de dormitancia. En este caso las células tumorales pueden residir por décadas en los pacientes antes de recurran como tumores primarios o metástasis, lo cual se evidencia por ejemplo en ratas a quienes se aplicó dosis bajas de carcinógenos, sin que desarrollaran tumores luego de un periodo de tiempo, pero que al administrársele anticuerpos monoclonales contra las células T y INFY, se desarrolló rápidamente el tumor en la zona de aplicación inicial. En este caso la inmunidad mediada por la IL-12, INFy, CD4 y CD8, limitan a las células tumorales en este estado.
3. Escape: Las células tumorales evaden el reconocimiento inmune y/o destrucción. Para ello, se valen de la perdida de la expresión antigénica tumoral, que se da por la no expresión de antígenos hiperreactivos, perdida de proteínas del MHC tipo I, y la no expresión de epítopes antígenicos para ser presentados al MHC I (Figura 4). En base a estas observaciones se propone que la inmunidad e inflamación y la oncogénesis serían fenómenos, por lo menos en algún momento, excluyentes ${ }^{30-33}$.

En este sentido, ha resurgido la imunoterapia como arma terapéutica contra el cáncer. Se ha descrito una adecuada y prolongada respuesta en pacientes con melanoma metastásico por administración autóloga de linfocitos CD4 y CD8 activados ex-vivo que evitaría el fenómeno de Escape de las células tumorales ${ }^{34}$. En el 2010, la FDA aprobó el uso de inmunoterapia (Sipuleucel-T), que consiste en la administración autologa de células mononucleares incluyendo células presentadoras de antígeno, que han sido activadas ex-vivo para el tratamiento de cáncer de próstata metástasico hormono-refractario. Es así, que se inicia y se viene desarrollando la inmunoterapia, considerando la observación inicial de la inmunovigilancia asociada a la respuesta $T h 1^{35-37}$.

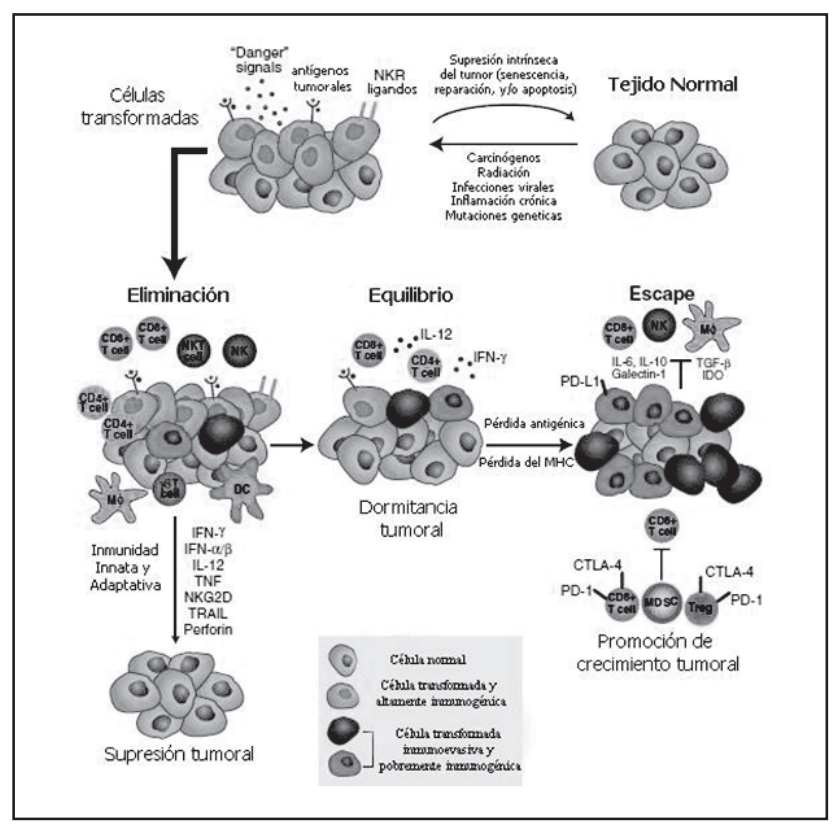

Figura 4. Concepto de regulación inmune en el cáncer. Se observan las diferentes fases secuenciales [(figura adaptada de (30)].

En sentido opuesto, la presencia de células Treg, y su respectivo perfil anti-inflamatorio, se asocia a un menor tiempo libre de recaída de tumores como de pulmón, estomago, hígado y ovario. Existe un incremento sistémico de Treg en estadios avanzados de cáncer, y además un radio Treg/Tefector se considera de 
valor pronóstico. Los tumores adicionalmente liberan IDO, adenosina, que es producto de la hipoxia del ambiente tumoral, y que promueve las Treg, así como la producción de CCL28 favoreciendo su inmigración. En este sentido, es congruente también la asociación entre inmunodeficiencia asociada a transplantes y aumento en la prevalencia de cáncer ${ }^{30-33,38}$.

Por otro lado, el cáncer también es vinculado a un estilo de vida occidental, obesidad, excesiva ingesta de proteínas animales, lo cual se relacionaría no solo a un déficit alimentario, sino que condicionaría un estado de anergia inmunológica. Por esta razón existe una asociación estadística en los países desarrollados y mayor prevalencia de canceres como el colon, recto, próstata. Por ejemplo, existe una mayor incidencia de cáncer de colon y recto en países como Australia, Alemania, Estados Unidos, Canadá, Nueva Zelandia, a comparación de países de África, Sudamérica, o en India y Pakistán. El cáncer de próstata tiene una mayor tasa en Estados Unidos y una menor tasa en Asia y norte de África, lo cual estadísticamente se ha asociado al mayor consumo de grasa animal per cápita. Sin embargo, la occidentalización, actualmente involucra a países en vías de desarrollo, previéndose un aumento del diagnostico de cáncer de un $56 \%$ en el 2008 a más de $60 \%$ en el $2030^{39}$. En base a estos hallazgos, la nutrición precisa un lugar especial en la respuesta inmune y cáncer, habiéndose vinculado algunos inmunonutrientes en su prevención. Por ejemplo, se ha observado un riesgo 2-3 veces mayor de desarrollar un adenocarcinoma gástrico en pacientes con anemia perniciosa y déficit de vitamina B12, lo cual disminuye la proporción de linfocitos T CD8 y suprime la actividad de las células NK; asimismo, genera una forma inactiva del folato como 5-metiltetrahidrofolato, que conlleva a un déficit en la síntesis de purinas, afectando la síntesis de ADN, ARN y producción de inmunoglobulinas. Un déficit de piridoxina también suprime la acción Th1, y promueve la Th2, y una mayor ingesta de vitamina $E$, promueve la respuesta Th1 y suprime la Th $2^{40}$.

\section{CONCLUSIÓN}

La inmunoregulación Th1/Th2, es un fenómeno continuo y dinamico que obedece a un entorno tanto fisiológico como fisiopatológico, en donde en ocasiones se requiere la prevalencia de una respuesta sobre la otra. Una respuesta Th1 es requerida como parte de un proceso inicial en el embarazo, y en otras ocasiones interviene como respuesta a una noxa tipo carcinógeno. Una disregulación a esta respuesta de manera exagerada se puede observar en enfermedades autoinmunes. Por otro lado, una respuesta exagerada Th2, la observamos en enfermedades con un perfil inmunoalérgico, pero en otras ocasiones una respuesta Th2 será necesaria junto a la Th3 para el mantenimientoy manejo de un transplantado. La respuesta si bien puede ser multifuncional, solo posee un sentido, y depende de la labor clínica encontrar el sentido correcto.

Financiamiento: Autofinanciado.

Conflicto de interés: Los autores declaran no tener conflictos de interés en la publicación de este artículo.

Recibido: 26 de septiembre

Aprobado: 14 de diciembre

\section{REFERENCIAS BIBLIOGRÁFICAS}

1. Zygmunt, Veldhoen, $T$ Helper cell Differentiation: More than just cytokines, Adv Immunology 2011; 109: 159-196.

2. Hamid, Tulic, Immunobiology of Asthma, Annu Rev Physiol 2009, 71: 489-507.

3. Rong, Distelhorst, Bcl-2 Protein Family Members: Versatile Regulators of Calcium Signaling in Cell Survival and Apoptosis, Annu Rev Physiol 2008, 70: 73-91.

4. Sabat, Grütz, Biology of interleukin-10, Cytokine \& Growth Factor Reviews 2010; 21: 331-344.

5. Iwakura, Ishigame, Saijo, Nakae, Functional Specialization of Interleukin-17 Family Members, Immunity Review 2011, 34 (25): 149-162.

6. Garofalo, Cytokines in Human Milk, The Journal of Pediatrics 2010, 156 S36-40.

7. Kaiko, Foster, New insights into the generation of Th2 immunity and potential therapeutic targets for the treatment of asthma, Curr Opin Allergy Clin Immunol 2011; 11(1): 39-45.
8. Robinson, The role of the T cell in asthma, J Allergy Clin Immunol 2010; 126(6):1081-9.

9. Moreira, Hogaboam, Macrophages in Allergic Asthma: Fine-Tuning Their Pro- and Anti-Inflammatory Actions for Disease Resolution, Journal Of Interferon \& Cytokine Research 2011; 31(6): 485-91.

10. Leung, Liu, Fang, Chen, Guo, Zhang, The cytokine milieu in the interplay of pathogenic Th1/Th17 cells and regulatory T cells in autoimmune disease, Cellular \& Molecular Immunology 2010: 7: 182-189.

11. Kanasaki, Kalluri, The Biology of preeclampsia, Kidney International 2009, 76: 831-37.

12. James, Whitley, Catwright, Pre-eclampsia: fitting together the placental, immune and cardiovascular pieces, Journal of Pathology 2010, 221:363-78.

13. Piccinni, $T$ cell tolerance towards the fetal allograft. Journal of Reproductive Immunology 2010, 85: 71-75. 
14. Bulmer, Williams, Lash, Immune cells in the placental bed. Int J Dev Biol 2010, 54: 281-294.

15.Tsampalas, Gridelet, Berndt, Foidart, Geenen, Perrier d’Hauterive, Human Chorionic gonadotropin: A hormone with immunological and angiogenic properties, Journal of Reproductive Immunology 2010, 85: 93-98.

16. Yagel, The development role of natural killer cells at the fetal-maternal interface, American Journal of Obstetrics and Ginecology 2009, october: 344-50

17. Lash, Robson, Bulmer, Functional role of uterine natural killer (uNK) cells in human early pregnancy decidua. Placenta 2010 (24): S87-92.

18. Nagamatsu, Schust, The Immunomodulatory Roles of Macrophages at the Maternal-Fetal Interface, Reproductive Sciences 2010, 19: 209-18.

19. Chinen, Buckley, Transplantation immunology: Solid organ and bone marrow, J Allergy Clin Immunol 2010;125: S324-35.

20. Gökmen, Lombardi, Lechler, The importance of the indirect pathway of allorecognition in clinical transplantation, Current Opinion in Immunology 2008, 20: 568-574.

21. Afzali, Lechler, Hernandez-Fuentes, Allorecognition and the alloresponse: clinical implications, Tissue Antigens. 2007; 69(6): 545-56.

22. Cassis, Natural versus Adaptive Regulatory T Cells. Kidney Transplantation. Ed Karger 2005 (146): 121-31.

23. Rothstein, Immunosupression and Regulation: Cast in New Light? J Am Soc Nephrol 2006, 17:2644-46.

24. Cornell, Smith, Colvin, Kidney Transplantation: Mechanisms of Rejection and Acceptance, Annu Rev Pathol Mech Dis 2008; 3: 189-220.

25. Wood, Regulatory $\mathrm{T}$ Cells in Transplantation, Transplantation Proceedings 2011, 43: 2135-36.

26. Issa, Chandrasekharan, Wood, Regulatory T cells as modulators of chronic allograft dysfunction, Current Opinion in Immunology 2011, 23:648-65.

27. Wieckiewicz, Goto, Wood, T regulatory cells and the control of alloimmunity: from characterisation to clinical application, Current Opinion in Immunology 2010, 22: 662-66
28. Rook, Dalgleish, Infection, immunoregulation, and cancer. Immunological Reviews 2011, 240: 141-59.

29. Kölmel, Pfahlberg, Mastrangelo, Niin, Botev, Seebacher, et al, Infections and melanoma risk: results of a multicentre EORTC case-control study, Melanoma Res 1999; 9(5): 511-9.

30. Schreiber, Cancer Immunoediting: Integrating Immunity's Roles in Cancer Suppression and Promotion, Science 2011; 331: 1565-71.

31. Finn, Cancer Immunology, The New England Journal of Medicine 2008; 358: 2704-15.

32. Quezada, Peggs, Simpson, Allison, Shifting the equilibrium in cancer immunoediting: from tumor tolerance to eradication, Immunol Rev 2011 ; 241(1): 104-18.

33. Vesely, Kershaw, Schreiber, Smyth, Natural Innate and Adaptive Immunity to Cancer, Annu. Rev. Immunol 2011; 29: 235-7.

34. Rosenberg, Yang, Sherry, Durable Complete Responses in Heavily Pretreated Patients with Metastatic Melanoma using T-Cell Transfer Immunotherapy, Clinical Cancer Research 2011; 17(13): 4550-7.

35. Lesterhuis, Haanen, Punt, Cancer Immunotherapy-revisited, Nature Reviews 2011; 10: 591-600.

36. Pandolfi, Cianci, Pagliari, Casciano, Bagala, Astone, et al, The Immune Response to Tumors as a Tool toward Immunotherapy, Clinical and Developmental Immunology 2011: 894704. Epub 2011 Dec 5.

37. Mellman, Coukos, Dranoff, Cancer Immunotherapy of age, Nature 2011, 480(7378):480-89

38. Byrne, Mills, Lederer, Targeting Regulatory T Cells in Cancer, Cancer Research 2011; 71(22): 6915-20.

39. Jemal, Center, Desantis, Cancer Epidemiology, Biomarkers and Prevention. Cancer Epidemiol Biomarkers Prev 2010, 19:1893-1907.

40. Wintergerst, Maggini, Hornig, Contribution of Selected Vitamins and Trace Elements to Immune Function, Ann Nutr Metab 2007; 51: 301-323.

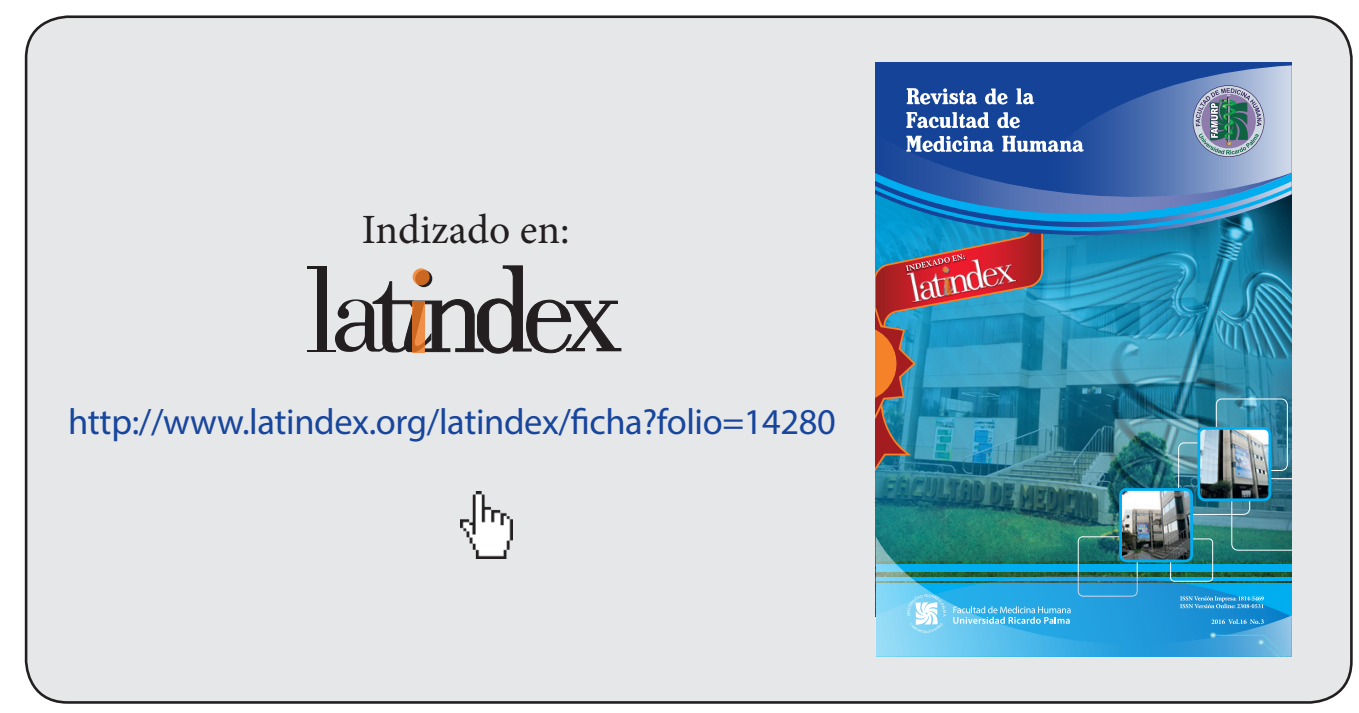

